\title{
How has Dewey's democratic theory influenced the development of a new primary school? A headteacher's perspective
}

\author{
Rupert Higham ${ }^{a}$ and James Biddulph ${ }^{b}$ \\ $\mathrm{a}_{\text {Institute of Education, University College London, UK }}$

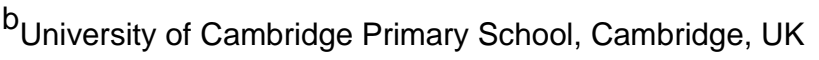 \\ CONTACT: Rupert Higham rupert.higham@ucl.ac.uk
}

\begin{abstract}
Pre-Publication Copy - Version of Record available here: How has Dewey's democratic theory influenced the development of a new primary school? A headteacher's perspective
\end{abstract}

Dr Rupert Higham (University College London, Institute of Education) in conversation with Dr James Biddulph (Headteacher of the University of Cambridge Primary School)

Rupert: Firstly, let me say congratulations on the recent award of your PhD.

What do you see as being the advantages of having begun your headship of the University of Cambridge Primary School (UCPS) as a PhD student? Were there any?

James: Well there were many practical matters of balancing both roles as student and headteacher and it was often hard and complex. When people ask me 'What have you learnt?' my response has been, 'the ability to manage complex information and to manage my time'. I think I have managed pretty well doing both. Doing the PhD and starting the school at the same time was a really profound way of linking my interest in theory or big questions about what education is and to consider what it could be ... it linked my academic interests and the work I did in schools. I saw that it was a process of responding to the relentless questioning that I felt was a part of my everyday work: 'how do I strengthen my own gut feeling that this is the right thing to do in a school?' Without doing the PhD it would have been more tricky because the access to great thinkers and researchers, supported by my supervisors Professor Pam Burnard and $\mathrm{Dr}$ Mandy Swann provided a platform to develop and have the discourse, or the language, or the understanding to be able to argue whatever position I was taking (Biddulph 2015).

So you found the process was somewhat symbiotic - in the sense that the problems that you encountered go back into your questions about theory?

More than that really. In setting up a new school, we were largely given a blank piece of paper, positioned within the UK accountability framework in place (like Ofsted), but the blank canvas means you have to ask questions about why you do things. So, for example, in defining how we might organise the space in the school, we could have just done it the way we've or others have done in other schools. But to really be a University Training school that is rooted in principles of research and democratic notions of education - we had to ask what does that really mean? Without doing a PhD it would have been very difficult for me to have that kind of nuanced understanding that arises when you are doing deep study for a period of time. The PhD required a courageous philosophical response to these ongoing questions.

Do any examples come to mind where you had those deep ideas, that launched onto the canvas and took shape and then perhaps fed back into your thinking and research?

Well in comparing ourselves with a number of free schools that have opened up, there seems a view, especially in inner city schools, that schools need to be created to be very strict, with children who do what they are told and are very compliant. There are a number of schools in the press recently that have that kind of ethos: a no excuse culture, high expectations everyday, disciplined approaches etc. Of course, I do not advocate an excuse culture of low expectations where children are given complete free reign. So, in trying to understand what our school would be, we had to ask questions of ourselves about the culture and ethos we wanted to create. You know, it is often said that children are the heart of a school. But that phrase just seems to have become meaningless, so we were saying what does it really mean if a child is at the heart of a school, how would you know? So with that question in mind we started to look at our school. I have always been interested in Maxine Greene's work (Greene 1998). Indeed, the strapline of the school: Releasing the Imagination - pays homage to that book and her views. So how do we critique the assumptions we make about the child being at the heart of the school? It required us to think differently about how children come into the school. The practicalities of coming in and out, and moving around the building. About how the behaviour management system, which we call a relationship management system, would work. How such practical matters support the children to feel they are at the heart of the school. Do the children really understand that they are the most important and does the youngest child with the quietest voice have an opportunity to speak out the loudest? That has been the constant testing point. Someone had to think of an idea before we started, but increasingly it evolved through how we 
engaged with one another in the school, where children can feel that they can speak and have their view not just heard but enacted upon.

This motto that the school has: 'Releasing the Imagination: celebrating the art of the possible.' Can you say a bit more about what that means to you and how you try to realise that as an ambition and a reality in the school?

It's meant to be a provocation. It's very difficult to define what those two phrases mean. And although it started with me being interested in Maxine Greene's work and that whole critical view of education, the art of the possible came from Dame Alison Peacock, and in bringing those two ideas together, we intended to provoke a positive and hopeful questioning about what education could be about in the twenty-first century. We wanted it to be a statement that people also ask 'what does it mean?' and start talking about it. So, through dialogue and professional conversations in staff rooms and along the corridors, in discussions with parents, we could play around with what that really means. For me it meant the idea that we are not just creating children who can pass tests at the end of year 6 , but we are trying to develop young people to be compassionate citizens. Our curriculum model has compassionate active citizens at the heart of the work we do. So that links with the social imagination of what's possible. How do children know what's possible in a world that is increasingly complex? Releasing the imagination suggests that we are not going to limit the notion of hopeful possibility in education, saying we just can't do that because it's not done in schools. Instead we can try and allow ideas, encourage ideas to come, nurture, provoke, define and redefine the what, where, why and how of education. Through dialogue there is an opportunity to deepen our own resolve about what's right for our children. And so in our first two years, the professional development focus was on nurturing a trusting staff team who could open up discussion about the possibilities of releasing the imagination and celebrating the art of the possible - which we thought was a vital necessity in an educational accountability context that seemed limiting.

\section{Can you think of an example where something more like the impossible has become possible through the application of that philosophy or by following through that philosophy?}

Every part of our school day is an opportunity for learning. Well, lunchtime is often seen as a break from children and a break for children but we see it as a vital part of learning, as part of their day. We wanted a family dining service and that takes a lot of effort and thinking and requires a lot of different ways of thinking about how you move children around space, how you create an experience that provides an enabling space for community making whilst eating together. Also the outdoor space, being very large (and I am not complaining about that for sure!), required us to think about space, which, as it happens linked so closely with my PhD study that evolved the notion of enabling spaces. How would we engage young learners out there?

Initially there was a lot of 'that's a health and safety risk - we can't do that, there are not enough adults in the playground'. There were lots of lists of things of why we couldn't do something in school. Some parents even thought the seeming chaos of our thinking, which I would define as an important part of the process of creating the very best ideas, would not give their children the best experience. But we had to hold our course and believe in ourselves. That is where I saw my role as head (and academic researcher) as influential and important: to create a space of trust and courage to take risks and run with ideas ... knowing full well that countless mistakes would be made.

But we flipped these initial concerns on their head - it became part of a mission to seek responses to the question, "how do we create an experience at lunchtime that allows children to be themselves, but also allows some really good social learning knowing that adults are part of this process. We did not want the adults policing health and safety, checking the playground or at lunchtime doing the same thing or checking whether people have eaten. Rather we wanted them engaging in discussions about life or the social aspect of being in a school.

It's a question of starting points then. Instead of starting from a 'norm' of what lunchtimes are supposed to look like in a primary school and how difficult it would be to change that to this vision, it was starting with a vision, putting aside how things happen to have been done elsewhere and realising that instead?

Yes I think so. And another example would be our approach to reading which started initially in the first few weeks in a very traditional 'guided reading' and 'phonics' way, but we quickly realised that this was not innovating, so we started thinking about what reading could be. How could we 'release the imagination?' We found experts in the field both at the Faculty at Cambridge and the Open University and contacted Mary Anne Wolpert and Professor Theresa Cremin. Their encouragement for us to use their research and thinking to be able to re-think how we engage young people in reading marked the first images on our blank canvas really but it was definitely taking a risk because there is not much time or space in the UK education system to make mistakes and learn from these. Or that is how it feels. But the art of the possible is about taking risks, and celebrating those small moments of tinkering with practice and again, as Headteacher, I had to find courage in myself to trust my new colleagues, whom I do respect and trust, but I also felt the enormous pressure of inspections and other external frameworks. To be honest, there were moments of self-doubt and middle of the night panic when I considered the tension between the risk taking tinkering of practice and the looming pressure of Ofsted inspections. As I said, teachers are in a position of risk the whole time and so are headteachers, because of the accountability framework and the high expectations that people rightfully have of schools and what happens in them. But if you want educators to be risk takers, you have to allow them take risks and make mistakes, so celebrating the 'art of the possible' is about supporting people in those small steps to overcome those spaces of uncertainty and risk and it is to celebrate those moments: otherwise, the imagination can never be released. 
So having structures of support and understanding in place if risks don't pay off, or indeed learning from them regardless, is very different from people feeling vulnerable and allows them to try something different.

Earlier you were talking about how children use the space in the school. I have had the privilege to see and it is an extraordinary space inside and out. ${ }^{1}$ How does the space impact on the pedagogy and culture of your school and could you imagine how these ideas for your school might be possible in, say, a humbler, more traditional building?

Well, as I mentioned earlier, another synergy between my $\mathrm{PhD}$ work and setting up this school was that in the PhD I focused on the notion of space and different forms of space - spaces I call uncertainty, enabling spaces, playful spaces, quiet spaces. The notion of space became really important in my study as a conceptual way of understanding creative learning in children's homes and in terms of the school, I was there when the space was created. I was there on that cold November day when from the mud fields in dark winter a structure brought life to the space. And then it became an enabling space as we moved in and the children first took their coats off and came inside full of anticipation. So, there was a kind of journey of space-making; from space making that then became a place in which something was to happen. The space in this school is beautiful, as you have seen. Julia Barfield MBE, the main architect on the design was sensitive to the research about school spaces and it's rooted in principles of trust and openness - there are no doors on the classrooms, so we all can learn from one another and with one another and children are trusted to go outside into different spaces and learn and be learners.

Having said that, the space is tricky because it doesn't conform to any other kind of school that l've ever worked. What is powerful about it is that the principles are rooted in deep thinking that have come from many other school contexts as the architects researched different kinds of schools. So the space causes us problems in many ways because we have to think about how we make it work. You can't shoehorn in traditional furniture, we can't set up classrooms in the way that you might do normally. Most recently the space seems to have become more fluid - they are fluid spaces as teachers move their classrooms around more regularly, they are beginning to see that the glass wall between outside and inside is actually a false wall and that the outdoor space is an extension of the classroom rather than it being just a space you use in the summer or when you go outside as 'Forest School'. Maybe it's becoming a broader concept - the space is wider than the classroom. Maybe there are some principles that any school can adopt. For example there is a school down the road, Hemingford Grey, whom we visited - they knocked all their walls down inside so there are two hubs and a big space, the children do project work, they are trusted to go out and commit themselves to different tasks that they will finish by the end of the week and will be able to assess them. Kate Fox is the headteacher there and she has been inspiring to me because she has honestly shared the joys and pitfalls of making new thinking about spaces in school. She has the professional hopeful courage necessary to inspire her staff to believing it will work: we can really trust children through setting the highest expectations about what they can achieve. So there are schools up and down the country in more humble buildings than our newly designed one who are playing around with internal structures and their own spaces, through the way they paint them, through the aesthetics that they are creating. Our school was designed with a principled, research informed approach but that does not restrict other schools to consider the principles upon which they create new spaces that enable new forms of learning and teaching that raise expectations and standards for children. I hope that this is the case when people visit us and they don't leave thinking, 'Oh of course it's fine for you, you've got a lovely building.'

There's a subtle distinction between space and place whereby place is space plus imagination plus ambition or intention. This made me think when you were talking about the walls disappearing between inside and outside, you mentioned some principles from Dewey there that interested me because you also talked about 'compassionate citizenship'. That makes me reflect on the idea of schools becoming more 'porous' as it were, of being not just linked to their grounds but linked to the wider community and I wonder if that's integral, or linked to your philosophy of compassionate citizenship - whether that happens just in the school, or how far that extends?

Our school has been on a building site for two years and around us, from the mud fields, there have grown new spaces, houses, soon to become home places when people start living their lives there. There is a sense that the children are part of this new growing. They are growing up themselves but they are also seeing a new district grow around them and they'll see people moving in soon and living and walking up and down the streets and I think that that will open their eyes to the sense that we are no longer a building site and we are part of the community in this north part of Cambridge. It is great to be able to work with artists, with an organization called Artscapers who are part of the North Cambridge Development who have worked with children in our schools and other schools. They have been involved in documenting, in artistic ways, their response to the spacemaking as it evolves around them and their contribution to that spacemaking. Children need to be involved if they are to understand their roles and responsibilities as citizens who engage in a community in compassionate and respectful ways. It is done with children and not on them.

So in a way they are part of bringing that community into being at the moment but there is also another chapter to come as more people and life come to those bare fields.

In looking for opportunities for children to get out to breathe life into the streets, as it were, I have engaged with the new community centre next door and we have successfully received a grant for the children to do an art project that will connect communities through the establishment of, what we hope will become an annual carnival where they take over the streets, so, in this way, the children are bringing life into the streets. So there will be a lovely symbolic movement from our space, through art, in the social imagination 
that Maxine Greene talks about into celebrating the possibilities as we stretch out beyond the walls of our circular building. Using art to move beyond the confines of the school gates.

And with yours being such a beautiful school in its own right it's all the easier for it to become a bubble.

And I feel very sensitive about that as well. Yes, of course but this school as at the heart of this new residential development and it is strategically very important that it is seen as right in the middle of what's going on and these children are the future of the community. Our University Training School status and aspiration is to be a school that is outward looking, with a staff team that looks to collaborate with others in their own diverse contexts. We want, and will strive to become, a beacon of professional learning and not an inward-looking 'bubble' in a nice building on the edge of Cambridge.

You and UCPS were kind enough last year to host some of the events during our Dewey Conference. Have any of the ideas in 'Democracy and Education', or those emerging from the conference and the work around that, influenced your thinking in any way?

It was great to meet so many people from the conference and how pleasing that these connections have led to my being invited to write a chapter in a new book about the notion of an international 'Orbital Classroom'. That we are all educators and our classroom is the world and that we can all learn from one another came across most strongly in the conference delegates with whom I spoke. So from that conference arose the opportunity for me to contribute and to learn with colleagues. I gave a seminar to about 150 Italian teachers and scholars in Sicily so even in my own practice and increasingly in the practice of my teachers, the learning and teaching and educating is not just within our circular building in North West Cambridge. There is a bigger story to tell and although we are now a fledgling, we are learning to stretch our wings and beginning to see the horizons of limitless possibilities if we take courage and see education more broadly. How do we connect more widely and see ourselves as an educating community that is global? How do we interculturally connect and build bridges so that all our children from all the diverse diversities in our numerous communities can benefit? How do we truly provide an education that empowers, enriches and enables children to be the future possibility change makers? The orbital classroom is a nice image.

And it links well into an agenda around global citizenship - a nice metaphor.

I think it's important not to be tokenistic when considering such ideas of intercultural connecting. It is so easy to fall into the trap of doing the penpal writing projects: 'Let's write to children in another country and they will write back.' Not sure that engenders global thinking or citizenship. Really finding the ways to engage with one another in theoretical ways as well as practically is important. Often governments and policy writers go straight for things like, what technique we can borrow from China say, and transplant it here. Rather than what can we learn from the principles of their tradition of education? What can we translate rather than transplant to our schools? My PhD work about intercultural education and interconnectivity brought new thinking into our decision-making - how do we learn in spaces that connect us with one another?

Learn from the difference between us and don't just bolt on different things, but learn from the perspective that might challenge and refresh our own practice?

Difference is essential - it helps to nudge thinking rather than the view that we need to mold ourselves in that image. The intercultural thinking that arose in my $\mathrm{PhD}$, which brought to light another theoretical thinker whom I was inspired by, Helene Cixous (1994). The idea of being tinted with the other became significant especially when we realise we are all the other at some point and in different contexts in which we engage in life. So it was in the inbetween spaces where we are tinted and something new can arise, if we remain humble and self-critical.

So research is built into the values and aims of the University of Cambridge Primary School - in some senses even the space. How would you describe the role and the impact of research on the school?

We are still very young as you know and our main priority has been to ensure that we can create a brilliant school for children who live that same experience day in day out. We couldn't apologise and say we can sort that out or do that next year when we have done some research. So, the Primary School part has been the most important and has taken most of the time. But increasingly, from the publication of our own book in the first year (Gronn and Biddulph 2016), there was a nod to our aspiration to be a research informed and research generating school, and to consider how we document and how we understand beneath the activity of the school. How do we understand what it means and what is going on beneath the surface? That's a 'leitmotif' that goes throughout our thinking. Most recently, as a head, I am looking at HR matters. I am working with somebody who is doing an Ed.D. at the Faculty of Education at Cambridge. He is researching the recruitment and retention of new teachers to find reasons why they are leaving so quickly into their career. We have been working together to document some changes that we are going to make next year to find ways of mentoring and coaching new teachers, to show clearer stepping stones for teachers joining the profession and their ongoing journey. He is bringing poignant research he has read about in relation to retention and recruitment of teachers that will align in the work that we do together in the school. So for example, I wouldn't have thought in my previous headship to think about research into HR matters but what an exciting opportunity to really invent HR practice.

So something to be excited about and be innovative? 
And the word excitement means I feel that my own imagination has been released by working alongside somebody who is a practitioner, who's an expert in HR, who's doing an Ed.D. here, its again an opportunity to align theory with practice. And I see more and more on Twitter, that people are very excited about bringing research into their schools and into their practice. We've been very fortunate to work with the PEDAL centre here. They are looking at playful learning and the Lego play into writing project. We've done some work with Pam Burnard in understanding what happens when you bring a piece of artwork, a

sculpture into a school. And that has resulted in a book chapter written by a Teaching Assistant, a teacher, academics and myself. Schools all around the country do this, they bring artists in, they bring experiences into school, but to document what is going on and to try and analyse the experience of children and the experience of teachers, brings to the surface the possibilities, then we can celebrate those possibilities and embed these in practice underpinned by theoretical thinking.

It is interesting the way you describe this because the way these things are normally talked about - research informed or research-led classrooms, - there are power struggles about the use of those terms, especially around the idea of the loss of agency. So and so says they have studied 100 schools and as a result you should do this. But what you are talking about is almost teacher led, or researcher informed research whereby you have relationships with active researchers, whose ideas and practices influence you, and you provide opportunities for them to think through, test and realise their own ideas. That seems a different approach from taking it from the page as it were. Taking it from the person perhaps. Does that resonate with you as a way you've engaged with research so far?

I think it has because my colleagues have gone to speak with those undertaking, for example, the oracy and dialogue work. They've gone to speak with colleagues like yourself or Neil Mercer and they have been learning something new and some of the complex literatures are being filtered - we are getting the kind of pithy, best pieces to read that will help us build our understanding. Another example is the Education Endowment Foundation (EEF) said that teaching assistants largely don't impact on pupils very much; that they do not contribute much to raising standards. Our teaching assistants here wanted to argue the case that they do have value and they do contribute, and they looked at the research that the EEF built their view on - Rob Webster ${ }^{2}$ and it said that in fact it's the deployment of assistants where the issue is, not the teaching assistants themselves (although lack of continuing professional development for these professionals also has a marginalizing factor I think). I was inspired when one teaching assistant came to me and said this is how you need to deploy us. Again l've never worked in a school where you have the space,; through the co-leadership work we have tried to engage in, and hopefully I have tried to model, so people come with their ideas, that the process is collaborative and that although we have different roles in achieving our common purpose, there is a communality in our work and in our decision making. There is a sense of what is possible and refuting the ideas that it has to be 'standards OR creativity' - the false polarities that exist throughout education discourse.

One final question I'd like to ask you. Would you say that the UCPS approach to Primary Education is broadly speaking counter cultural in our current climate? If, to some extent it is, how much agency do you feel you have as a head teacher and as a school, to work within your own educational vision as distinct from one that might be demanded by the wider culture?

I think the tension is very taut because on the one hand as a free school we are almost required to be innovative, to add to the marketplace in the marketization of education in this country. But on the other hand, we are limited by frameworks that are quite standards orientated in their thinking. And the myths that abound about the Ofsted accountability framework and what it does and doesn't want to see still exist within the wider education culture. So in some ways we are countercultural in that we want to release the imagination and to do that, we have to believe there is something more than just getting children through tests. There are very brave Headteachers, probably braver than me, who refuse to do SATs because they think in their schools, that education is more important. So they see accountability as different from the education of children. And very interestingly Amanda Spielman, the chief inspector for Ofsted has said something not dissimilar - that we've focused far too long on gaming the system and pushing beyond the bar they set externally, and haven't focused on the real business of curriculum and teaching and learning, so it seems there is a nice journey back towards John Dewey's work again, about asking those questions about what happens in the relationships in those educational contexts.

So he gives us the great image of 'growth that begets more growth' rather than forcing growth down avenues that then limit future growth by not providing the tools or the vision to enable one to see beyond those ends in view.

Yes, and that's what worries me about some approaches to education where it's top down and the compliant nature of young people is most valued; that doing what they are told and listening to what they are being told, sitting up, listen and pay attention in order to attract the teacher - obviously this can get results but in the long term, in my view, and this is not researched in any way, the problem is that we will have a generation of young people who don't know how to think and that is concerning. So, that 'growth begetting more growth' in some of those other teacher directive focused models would be limited. I was once told to consider two questions when dealing with children: the first, what do you want them to do? And the second, what is the reason for them doing it? So, for example, shouting at a class to line up will get results. The reason for children lining up will be in fear of the teacher. If that is the reason you want them to line up, through engendering fear, then that is an option. I would rather help children be aware of the shared spaces and agreed ways of conducting oneself in a community, lining up quickly and quietly to save time, to create order or to ensure safe passage for 30 children around the school. Perhaps the relationships will then be about respect and trust? 
It is inspired that Dame Alison Peacock is building the new Chartered College of Teachers, as a new institution to set the professional agenda, to take control over our professional funds of knowledge and to redefine what it means to be a teacher - as a researching, research informed educator.

\section{Is there a metaphor that springs to mind to illustrate walking that line between your vision and the standards against which you are held?}

I think there is one - people talk about communication being the most important thing in any organization but communication and translation would be the two words I would use because we are constantly rearticulating, translating what we want to do, what we try to do, and what we do do, to a number of different audiences all the time. We are held to account by Ofsted, and I think there does need to be some kind of accountability, so we try and re-articulate to those different organisations in a way that by translating it, it makes sense to them. And through that translation we can still hold true to our values and our purpose because broadly our agendas are the same - we want brilliant education for children, although the way we might go about doing it - the journeys are slightly different, so translation is key. But more hopefully, I like to use the image of a reservoir of hope; and for me, refreshing and refilling my own reservoir of hope has come about because of the academic work in which I have engaged throughout my career, in the masters in music and then education research, in the $\mathrm{PhD}$, and in my own personal interest in reading how others have considered what education and what life is and it could mean. So, a metaphor of a reservoir of hope is one I remember the most.

Notes

1. http://universityprimaryschool.org.uk

2. MITA Lead \& Researcher, UCL Institute of Education.

\section{References}

Biddulph, J. 2015. 'Beyond the school gates through the children's family front doors: a teacherresearcher's journey to theorise creative learning practices' in,.

Cixous, H. 1994. 'Preface'. In The Helene Cixous Reader, edited by S. Sellers, Abingdon: Routledge. Greene, M. 1998. Releasing the Imagination: Essays on Education, the Arts and Social Change. San Francisco, CA: Jossey-Bass.

Gronn , P., and J. Biddulph, eds. 2016. A University's Challenge: Cambridge's Primary School for the Nation. Cambridge: Cambridge University Press. 